\title{
A INFLUÊNCIA DA AUTOESTIMA NO PROCESSO ENSINO- APRENDIZAGEM DE CRIANÇAS NOS ANOSINICIAIS DO ENSINO BÁSICO DAS ESCOLAS MUNICIPAIS DE TERESINA - PIAUÍ
}

\author{
Liliana Corrêa Rêgo ${ }^{1}$ \\ Maria Aparecida Santos e Campos ${ }^{2}$
}

\begin{abstract}
RESUMO: A alfabetização se caracteriza por oportunizar o acesso a uma educação de qualidade, nos primeiros anos do ensino básico e sua finalidade é evitar a exclusão social causada pelo analfabetismo. Por outro lado, impulsiona ou fomenta ações educativas e oportuniza a todos os indivíduos o acesso ao letramento. Durante o processo ensino e aprendizagem as variáveis mais relevantes e que têm recebido grande atenção por parte dos investigadores é a autoestima. Estudos demostraram ser um fator determinante para o otimizar rendimento acadêmico e social dos estudantes. Uma autoestima em alta traz benesses tanto ao aluno quanto ao docente.Assim mesmo, ser cognitivamente eficaz não é o bastante para garantir êxito acadêmico, profissional e pessoal, o que evidencia a importância da variável de cunho afetivo, (Morente, Filella e Ribes Castells 2015; Fernández-Berrocal y Extremera, 2002; Goleman, 1999). Nesse aspecto tem sido desenvolvidas numerosas pesquisas que põemem relevo que uma maior confiança nas capacidades próprias, autoestima saudável, confiança e alta perspectivas de autoeficácia produz no estudante um sentimento de valorização, confiança e responsabilidade, o que lhe permite cumprir com os objetivos propostos melhorando seu rendimento e por suposto seu estado emocional.
\end{abstract}

Palavras-chave: Alfabetização. Autoestima. Ensino- aprendizagem.

\section{INTRODUÇÃO}

A alfabetização engloba inúmeros aspectos e dois caminhos: de um lado se caracteriza por oportunizar o acesso a uma educação de qualidade, nos primeiros anos do ensino básico e sua finalidade é evitar a exclusão social causada pelo analfabetismo. Por outro lado, impulsiona ou fomenta ações educativas e oportuniza a todos os indivíduos o acesso ao letramento. Constituindo-se, portanto, no eixo central de

\footnotetext{
IDoutoranda pela FUNIBER - UNINI.E-mail: liliarego7o@gmail.com

${ }^{2}$ Doutora e docente FUNIBER - UNINI.
} 
qualquer processo de ensinagem. Durante o processo ensino e aprendizagem as variáveis mais relevantes e que têm recebido grande atenção por parte dos investigadores é a autoestima. Morente, Filella e Ribes Castells (2015) afirmam que a autoestima demonstrou ser um fator determinante para o otimizar rendimento acadêmico e social dos estudantes. Uma autoestima em alta traz benesses tanto ao aluno quanto ao docente.

Os benefícios envolvem contextos pessoais, políticos e econômicos, e estão relacionados com as emoções positivas advindas da superação das dificuldades, nesse aspecto produz um aumento da autoestima e confiança da pessoa em si mesma. O que segundo Benavot, (2008) provoca uma sensação de empoderamento abrindo caminhos para uma participação mais ampla e efetiva do indivíduo no contexto social. Por outro lado, estão as negativas originadas pelo fato de não saber ler e escrever que geram problemas de autoestima, insegurança e exclusão social nos sujeitos.

Assim mesmo, ser cognitivamente eficaz não é o bastante para garantir êxito acadêmico, profissional e pessoal, o que evidencia a importância da variável de cunho afetivo, (Morente, Filella e Ribes Castells 2015; Fernández-Berrocal y Extremera, 2002; Goleman, 1999). Nesse aspecto tem sido desenvolvidas numerosas pesquisas que põem em relevo que uma maior confiança nas capacidades próprias, autoestima saudável, confiança e alta perspectivas de autoeficácia produz no estudante um sentimento de valorização, confiança e responsabilidade, o que lhe permite cumprir com os objetivos propostos melhorando seu rendimento e por suposto seu estado emocional.

Nesse viés, os aspectos afetivo-social do indivíduo se relacionam com a satisfação de suas necessidades e interesses. No caso das crianças, facilita suas relações pessoais e a utilização dos conceitos necessários para a convivência social. Portanto, os desafios são superados no momento em que esta acredita que irá conseguir e motivase para tomar atitudes e alcançar o objetivo almejado. Deduz-se então, que a autoestima é uma ferramenta essencial e fundamental que dá origem ao desenvolvimento de processos para a formação de uma identidade positiva ou negativa, que leva o indivíduo aalcançar em sua vida adulta rótulas adequadas ou inadequadas em todas as ocasiões, inclusive na aprendizagem. $O$ sentimento de 
despreparo e negativismo exclui o indivíduo do mundo competitivo (Schultheisz \& Aprile, 2013).

A obtenção das habilidades para a alfabetização das crianças inseridas no sistema de ensino, seja ele particular ou público, ocorrem de forma sistemática e mediada por professores, devidamente capacitados em cursos específicos de Pedagogia para uma práxis adequada com atividades propícias a cada etapa do processo do desenvolvimento cognitivo, objetivando o alcance das metas delimitadas no processo de ensino e aprendizagem. Cabe ressaltar sobre a importância do clima motivacional na sala de aula,os professores devem acreditar no potencial da sua docência e na sua capacidade de motivar os alunos na sala de aula, considerando sempre a coesão do trabalho pedagógico no que diz respeito aos conteúdos programados nas bases curriculares de ensino, permitindo que os alunos saibam o que é, o que importa na aula, e qual o objetivo que o professor deseja alcançar com eles, essa decisão também empodera o aluno e lhe faz partícipe e construtor do seu desenvolvimento dessa forma dando-lhe responsabilidades inegáveis no processo..

O que vai de encontro com a afirmação de Gutiérez e Expósito (2015) quando explica porque a Inteligência Emocional facilita a consciência e a compreensão de nossas emoções, assim como, as dos outros, além de acentuar a capacidade de trabalhar em equipe graças a uma atitude empática e social. Para Escobar (2015, s/p) a avaliação do desempenho dos alunos é apenas um dos aspectos relevantes da relação ensinoaprendizagem. Yavorski e Santos e campos (2019, p.25) afirmam que:

O sucesso no processo de aprendizagem requer meios adequados para enfrentar os desafios da educação, da mesma forma, a formação do profissional da educação é um componente básico importante para uma educação inclusiva e de qualidade. As dificuldades apresentadas pelos alunos podem ser exitosas apartir da utilização de técnicas inovadoras, que os motivam na busca pelo conhecimento .

Para as autoras, as discussões originadas do tema educação de qualidade no país, ficou notadamente claro que se fazia necessário um olhar para a formação dos docentes, e da necessidade de melhorar a preparação dos profissionais da educação.Que segundo elas, 
da graduação em Pedagogia uma pós

-graduação, ou seja, uma especialização que lhes preparasse eauxiliasse no

trabalho com alunos... (Op Cit, p. 33).

Cabe salientar que a formação do professor influencia no processo ensino e aprendizagem do aluno.Yavorski e Santos e Campos (2019,p.37) opinam que:

\begin{abstract}
Precisamos dar opções para que os alunos continuem motivados a aprender relacionando o trabalho pedagógico a um contexto social mais amplo. (...) O professor em sala deaula deve ser um pesquisador e preocupar-se em buscar elementos que possam ser facilitadores da aprendizagem dosalunos.
\end{abstract}

\title{
1.3.A formação dos Professores Alfabetizadores
}

A formação acadêmica dos profissionais da educação modificou-se com o passar das décadas desde o professor leigo, o qual não possuía curso específico para o exercício do magistério no início do século XX, perpassando pelo advento da Lei de Diretrizes e Bases da Educação (LDB,1996), a qual enfatizou a importância de formação em curso de Licenciatura Plena para professores das séries iniciais, tendo como formação mínimao curso Normal, já extinto atualmente. O trabalho docente no âmbito do processo de alfabetização do educando torna-se cada vez mais essencial e relevante no sentido deque as classes das séries iniciais são objeto de delimitação de metas a serem atingidas cada vez mais cedo, ou seja, é cada dia mais exigido que a prática pedagógica seja mais eficaz em menos tempo, principalmente no Ensino Fundamental.

Já ultrapassado a questão da formação inicial do docente das séries inicias, fazse necessário então o olhar investigativo e pesquisador desse profissional nas classes de alfabetização, pois para que o seu trabalho seja desenvolvido com eficácia, é preciso que o professor compreenda de que forma seu aluno está entendendo a codificação e a decodificação para a formação de palavras e textos. Em apoio e atendimento a essa nova demanda, o curso de graduação em Pedagogia em seu currículo e estágio supervisionado, busca subsidiar e exercitar esse novo olhar de forma analítica para então colocar-se de maneira interventora frente à construção das hipóteses que o alfabetizando constrói ao longo do processo de apreensão da leitura e da escrita. São 
muitos os casos de profissionais da educação que saem do curso de Pedagogia ainda ávidos de fundamentação teórica além do que é estudado na graduação e cursam especializações específicas, no caso do tema aqui tratado, pode-se ressaltar o curso de Especialização em Alfabetização.

\section{A Formação Continuada}

Em se tratar do trabalho pedagógico, a formação acadêmica necessita continuidade e atualizações próprias de acordo com a política educacional do sistema de ensino em queo profissional está inserido, deste modo temos então o apoio da formação continuada, onde os sistemas de ensino disponibilizam e promovem palestras, reuniões para troca deexperiências, orientações de técnicos pedagógicos e ou encontros de estudo de nova legislação ou base própria, tais como: PCN's, BNCC, Diretrizes Nacionais, construção do currículo estadual, municipal, entre outros.

Em Teresina, a formação continuada especificamente na rede de Ensino Municipal, nas séries iniciais do Ensino Fundamental, os docentes têm encontros quinzenais, organizados por grupos de docentes e séries específicas, onde os formadores são técnicos da própria secretaria municipal, os quais já ministraram aulas nas séries e estãono exercício de sala de aula ou de supervisão escolar da mesma rede de ensino. Nestes encontros quinzenais a pauta é construída com base nas orientações quanto ao conteúdo a ser ministrado, com o foco nas habilidades pretendidas de cada série, ao longo do período letivo. As disciplinas alvo dessas formações são Língua Portuguesa, Matemática e Ciências.

O processo de alfabetização no ensino sistematizado em ambientes escolares constitui um desafio para professores das séries iniciais, principalmente em escolas públicas de periferia e, neste caso específico, em zona rural. Um elemento importante para o favorecimento do processo de alfabetização refere-se à autoestima do sujeito da aprendizagem, independente da sua faixa etária ou condição sócio-econômica. Segundo Mendes, Castelano, Martins \& Andrade (2017, p. ıо) “o indivíduo deve ser estimuladoa aprender, livre de repreensão ao errar, a sentir-se aceito e valorizado pelo seu potencial”. 
Neste viés, o olhar de valorização o qual cada indivíduo tem de si próprio, sendo este resultado daquilo que ouve dos outros ou de suas próprias vivências no ambiente induzo entendimento de sua autoestima, reconhecido em pesquisa realizada entre educadorese familiares de educandos, como estimulador do bom desempenho do crescimentocognitivo das crianças, em especial, na fase de alfabetização. Como se dá a influência que o desenvolvimento da autoestima exerce sobre crianças em fase de alfabetização constitui-se em alvo desta pesquisadora.

É importante ressaltar que pesquisadores brasileiros já executaram estudos e análises referentes à relação entre a autoestima e a aprendizagem, o artigo de Clarice Salete Traversini (UFRS) o qual tem a base na pesquisa realizada no PAS (Programa de Alfabetização solidária) trata justamente da relação existente entre autoestima e alfabetização, onde é enfatizado que a baixa autoestima é um obstáculo para o processo de alfabetização, como visto a seguir:

O sentimento de opressão e de inferioridade, a vergonha, o estigma por não saber ler e escrever e o temor do preconceito são condições geradoras de baixa autoestima. Isso constitui um problema para o desenvolvimento do Programa, visto que pode dificultar o processo de alfabetização. (Clarice, 2009)

No texto presente, segue a amplitude da relação entre autoestima e aprendizagem referente à etapa de alfabetização, nas séries iniciais do Ensino Fundamental regular. Destaca-se sob essa direção, os estudos de Clarice Salete Traversini, onde é exposto a crescente preocupação com este tema, desde meados de 1980:

O pressuposto de que a autoestima facilita o processo de aprendizagem expande-se com as pedagogias de base psicológica. No processo de alfabetização, observa-se, no Brasil,desde a década de 8o, o fortalecimento da relação entre autoestima e aprendizagem com as pedagogias construtivistas. Enfatiza-se o sucesso dessa relação nos processos de alfabetização ou escolarização das chamadas crianças em situação de fracasso escolar ou com dificuldades deaprendizagem. (Clarice, 2009)

Já ultrapassado a questão da formação inicial do docente das séries inicias, fazse necessário então o olhar investigativo e pesquisador desse profissional nas classes de alfabetização, pois para que o seu trabalho seja desenvolvido com eficácia, é preciso que o professor compreenda de que forma seu aluno está entendendo a codificação e a 
decodificação para a formação de palavras e textos. Em apoio e atendimento a essa nova demanda, o curso de graduação em Pedagogia em seu currículo e estágio supervisionado, busca subsidiar e exercitar esse novo olhar de forma analítica para então colocar-se de maneira interventora frente à construção das hipóteses que o alfabetizando constrói ao longo do processo de apreensão da leitura e da escrita. São muitos os casos de profissionais da educação que saem do curso de Pedagogia ainda ávidos de fundamentação teórica além do que é estudado na graduação e cursam especializações específicas, no caso do tema aqui tratado, pode-se ressaltar o curso de Especialização em Alfabetização.

O termo alfabetização dispõe sobre a capacidade do indivíduo em codificar e decodificar utilizando-se do sistema alfabético para a elaboração de palavras, frases e textos de acordo com a ideia ou mensagem a ser entendida ou transmitida inerentes às diversas situações do cotidiano, reconhecendo-se como o termo letramento a capacidadede fazer o uso social da leitura e da escrita.

A alfabetização se ocupa da aquisição da escrita pelo indivíduo ou grupos de indivíduos, o letramento focaliza os aspectos sócio-históricos da aquisição de um sistema escrito por umasociedade. (Amélia Hamze, 2016).

Para que se possa delimitar os níveis de escrita, visando um maior controle do desempenho e da evolução da criança no processo de alfabetização, tem-se como base os estudos de duas educadoras pesquisadoras Ana Teberosky e Emília Ferreiro a partir do embasamento das teorias de Vigotsky e Piaget escreveram o livro "A Psicogênese daLíngua escrita" e então enfatizaram a importância do entendimento das hipóteses de leitura e escrita dos educandos em fase de alfabetização analisando a evolução do aprendizado de crianças deste nível.

Durante o desenvolvimento das pesquisas sobre a evolução das hipóteses inerentes ao processo de alfabetização em crianças as autoras acima citadas formularam os níveis: pré-silábico, silábico e alfabético; posteriormente sendo os intervalos entre eles reconhecidos e reformulados agora como: Pré-silábico ( não diferencia letras de números e acredita que sinais gráficos representam a fala), Silábico ( diferencia letras denúmeros e entende que a palavra é formada por unidades sonoras 
e lê apontando uma ou

mais letras), Silábico-alfabético ( $\mathrm{faz}$ a relação da sílaba ao som mais perceptível à letra que escreve) e alfabético ( escreve palavras relacionando o som das unidades sonoras às sílabas, podendo cometer erros ortográficos).

Tal formulação esteve em vigor para efeito de delimitação dos níveis de leitura e escrita,orientado pela SEMEC do município de Teresina até o ano de 2018, período em que a pesquisa base desta dissertação foi executada em escola da rede municipal de ensino.

A ideia do termo ciclo de Alfabetização foi instituída pela necessidade de se consideraro processo de alfabetização com maior amplitude que apenas a apreensão do código alfabético, quando era delimitado a série própria para o alcance da competência de codificação e decodificação de palavras antes do advento da LDB alterada em 6 de fevereiro de 2006 pela lei II.274 a qual instituía o Ensino Fundamental a partir dos 6 anos de idade com sua duração de 9 anos. Após esta legislação a série denominada Alfabetização foi excluída, tendo como início do Ensino Fundamental a série nomeada como I응 ano e final desta etapa o $9^{\underline{0}}$ ano.

É de fato compreensível, pois o desenvolvimento da leitura e da escrita frente àscompetências de letramento, deve ser continuado em mais de um período letivo para o seu desempenho completo, tomando a princípio, as séries de $\mathrm{I}^{\mathrm{O}}, 2^{\mathrm{O}}$ e $3^{\mathrm{O}}$ ano.

O ciclo de alfabetização que era delimitado do $\mathrm{I}^{\mathrm{o}}$ ao $3^{\mathrm{o}}$ ano do Ensino Fundamental, agora vai até $\mathrm{o} 2^{2}$ ano, pois a concepção do termo "alfabetização na idade certa" tema doPNAIC, visa uma meta de que todos os alunos sejam alfabetizados no I ano; algo que está sendo desenhado desde 2012 quando foi criado.

É importante salientar que especialmente no Io ano do ensino Fundamental, o sistema municipal de Ensino de Teresina segue a orientação e as diretrizes do Programa Alfa e Beto do IAB (Instituto Alfa e Beto), logo, as formações continuadas para professores que ministram aulas para o $\mathrm{I}^{\mathrm{o}}$ ano da rede municipal de Teresina são embasadas nos livros da coleção do Programa Alfa e Beto, onde estão determinadas os conteúdos, habilidades específicas e sistema de avaliação da série na ordem e nos moldes do mesmo programa. 
No que se refere às turmas de $2^{-}$ano, os professores lotados nesta série do Ensino Fundamental recebem formação continuada quinzenalmente, ministrada por professores formadores selecionados entre os servidores efetivos em exercício da Secretaria Municipal de Educação, os quais orientam as turmas de professores cursistas quanto ao conteúdo a ser trabalhado, como também promovem a troca de experiências entre os integrantes das mesmas e o monitoramento dos dados referentes ao desenvolvimento da aprendizagem e alcance dos resultados.

Segundo João Batista de Oliveira, presidente do Instituto Alfa e Beto, para ser alfabetizado, uma pessoa precisa compreender de que forma o princípio alfabético é relacionado com os fonemas existente nas palavras, relacionando a unidade sonora com as sílabas escritas:

O primeiro passo para alfabetizar consiste em ajudar a criança (ou adulto) a compreender o princípio alfabético. Esse passo,por sua vez, requer o desenvolvimento da consciência da existência dos fonemas e do fato de as letras representarem essesfonemas. E, a partir daí, a criança precisa aprender ascorrespondências entre fonemas e grafemas. (João Batista, 2014)

Entende-se por autoestima a valorização e o reconhecimento que a pessoa tem de si mesma, podendo ser de maneira positiva constituindo-se em uma boa autoestima, ou mesmo quando de forma negativa constituindo-se na baixa autoestima. Quando se trata desses termos, o âmbito visualizado parece ser somente o da Psicologia, porém se o indivíduo não reconhece valores positivos em si mesmo, a crença de que ele é capaz de aprender algo se torna mais complexo, enquanto que em estudantes com uma visão positiva de si próprio, este coloca-se confiante frente ao desafio de conhecer novos saberes.

Para maior esclarecimento do tema, temos a visão de autoestima segundo BRADEN, (1969):

Auto-estima é a disposição de experimentar a si mesmo como sendo competente para lidar com os desafios básicos da vida e ser digno de felicidade. É confiança na eficácia da nossa mente, na nossa capacidade de Por extensão, é a confiança em nossa capacidade de aprender, tomar decisões e decisões apropriadas e reagir efetivamente à mudança.Também é a experiência que o sucesso, a realização, a felicidade da realização são corretos e naturais para nós. de tal confiança é óbvia, esse é o perigoquando ele está faltando.” 
Partindo do pressuposto que o indivíduo que mantém uma visão de si mesmo, daquilo que ele pensa de si próprio de maneira positiva tem a disposição necessária paraenfrentar as diversas situações não vivenciadas anteriormente e se perceber digno de experimentar o sentimento de felicidade, então este ser se coloca em atitude de abertura ao novo, de encorajamento às vivências futuras e seguindo esta linha, o sujeito com a autoestima positiva se mostra em prontidão ao aprendizado de acordo com o seu nível de maturidade cognitiva.

Em uma sala de aula de Ensino Fundamental, o(a) professor(a) é capaz de identificar aquelas crianças que acreditam no seu potencial de aprendizado e outras que não se consideram capazes de compreender as orientações e direcionamentos propostos pelo docente na prática de sala de aula.

Cabe ao profissional da Educação motivar a classe de alunos no sentido de enfatizar queo conhecimento pode ser construído pelos mesmos e que o professor está como um mediador e facilitador do processo de aprendizagem colocando-se para o auxílio e apoiodurante a execução das técnicas específicas para cada habilidade e competência inerente à série específica e no caso do estudo deste trabalho, das competências de leitura e escrita.

Para que o profissional tenha a postura verdadeira de acreditar no potencial de seus alunos, é necessário que, ele próprio acredite em si mesmo e se veja como ser capaz de atuar com eficácia no processo de mediação do conhecimento.

Quanto ao respeito de si mesmo e dos outros Paulo Freire sabiamente indica a observação de si próprio como educador:

Como educador, devo estar constantemente advertido com relação a este respeito que implica igualmente o que devo ter pormim mesmo. Não faz mal repetir afirmação várias vezes feita neste texto - o inacabamento de que nos tornamos conscientes nos fez seres éticos. O respeito à autonomia e à dignidade de cada um é um imperativo ético e não um favor que podemos ou não conceder uns aos outros.(FREIRE, 1996). 


\section{METODOLOGIA}

O objetivo final deste estudo foi observar o desenvolvimento da autoestima e conhecer sua influência no processo de obtenção do código alfabético, de que maneira esta conquista se dá e qual a sua influência no alcance dos seus objetivos e no desenvolvimento positivo ou negativo da autoestima relacionada à aprendizagem dessesestudantes matriculados e frequentes nos anos iniciais do Ensino Básico

Local da pesquisa: A Escola Municipal Campestre Norte está inserida em Povoado dezona rural de mesmo nome e conta com uma quadra poliesportiva, 4 salas de aula, 5 banheiros, pátio escolar, diretoria, secretaria, sala de professores e cantina; onde trabalham: o diretor, uma coordenadora pedagógica, 4 professores, I assistente de

alfabetização, pessoal de cantina e manutenção.Tem um otal de 97 alunos distribuídosentre turmas de $\mathrm{I}^{\mathrm{O}}$ ao $5^{\mathrm{O}}$ ano nos turnos manhã e tarde no ano de 2018 .

Metodologia: O estudo com os alunos foi realizado ao longo do ano letivo de 2018, com base nas visitas em sala de aula para a verificação e seguimento da aprendizagem por meio dos testes próprios da escola. O objetivo final deste estudo foi observar o desenvolvimento da autoestima e conhecer sua influência no processo de obtenção do código alfabético, de que maneira esta conquista se dá e qual a sua influência no alcance dos seus objetivos e no desenvolvimento positivo ou negativo da autoestima relacionada à aprendizagem desses estudantes matriculados e frequentes nos anos iniciais do Ensino Básico.

Amostra I: A amostra não probabilística foi composta de 70 alunos com faixa etária de 6 a 9 anos do $I^{\circ}$ e $2^{\circ}$ ano (em fase de obtenção do código alfabético) dos turnos (manhã e tarde) e 04 professores e um diretor.

Amostra 2: $\mathrm{E}$ a equipe pedagógica é composta de of profissionais: 4 professores e I pedagoga. A equipe docente que os atendia, incluindo a assistente de alfabetização que ministrava reforço específico para os educandos com baixo rendimento das turmas 
citadas.

Critérios de inclusão: que estavam devidamente matriculados e frequentes na escola. Instrumentos desta pesquisa: Observação da prática pedagógica em sala de aula, entrevistas com questionário com perguntas abertas e fechadas para professores e assistente de alfabetização acerca da concepção que estes têm sobre a importância da autoestima no processo de alfabetização. Para a análise do estudo se utilizou a análise de conteúdo.O estudo com os alunos foi realizado ao longo do ano letivo de 2018, com base nas visitas em sala de aula para a verificação e seguimento da aprendizagem por meio dos testes próprios da escola. Com relação aos docentes, foi realizada pesquisa por meio de questionários com professores e gestor da escola e foram aplicados ao final do mesmo ano. Este estudo se realizou com base na análise do processo de aprendizagem dos alunos de $\mathrm{I}^{\circ}$ e $2^{\circ}$ ano ( em fase de obtenção do código alfabético) com faixa etária de 6 a 9 anos da Escola Municipal Campestre Norte em zona rural de Teresina.Com relação aos docentes, foi realizada pesquisa por meio de questionários com professores

e gestor da escola e foram aplicados ao final do mesmo ano. Este estudo se realizou com base na análise do processo de aprendizagem dos alunos da Escola Municipal Campestre Norte em zona rural de Teresina.

\section{Procedimentos}

Para que as informações com os dados passíveis de análise fossem tomadas, foi realizada uma pesquisa de campo onde a pesquisadora exerce o cargo de coordenadora pedagógica, como instrumentos foram utilizados a observação da prática pedagógica em sala de aula e entrevistas por escrito para professores, diretor e assistente de alfabetização sobre a concepção quanto à autoestima, quais as atividades promotoras do desenvolvimento da própria autoestima e dos alunos em fase de alfabetização e quais observações os mesmos faziam da influência do desenvolvimento da autoestima em relação à construção cognitiva de estudantes das séries iniciais.

Ao final do ano letivo foram entregues os mesmos questionários à equipe docente e ao diretor da escola, observando-se uma mudança nas respostas, as quais 
foram embasadasna própria vivência e na verificação do crescimento intelectual dos estudantes.

\section{Resultados}

Foram observadas crianças na faixa etária de 7 a 9 anos, as quais já haviam cursado o Ensino Infantil em instituição educacional da mesma comunidade, tendo sido iniciadasna obtenção do código alfabético.

As turmas analisadas estavam divididas em 2 salas de $\mathrm{I}^{\circ}$ ano (II $\mathrm{AM}$ e II AT), totalizando 33 alunos e I turma de $2^{\circ}$ ano (I2AM) com i9 alunos, os quais foram diagnosticados em março, no início do ano como:

Nível de Escrita

\section{Gráfico I}

Turmas de $\mathrm{I}^{\circ}$

ano

- Nível Pré-silábico: 6 alunos (I8\%)

- Nível silábico: 20 alunos (6r\%)

- Nível silábico-alfabético: 5 alunos (15\%)

- Nível alfabético: 2 alunos (6\%)

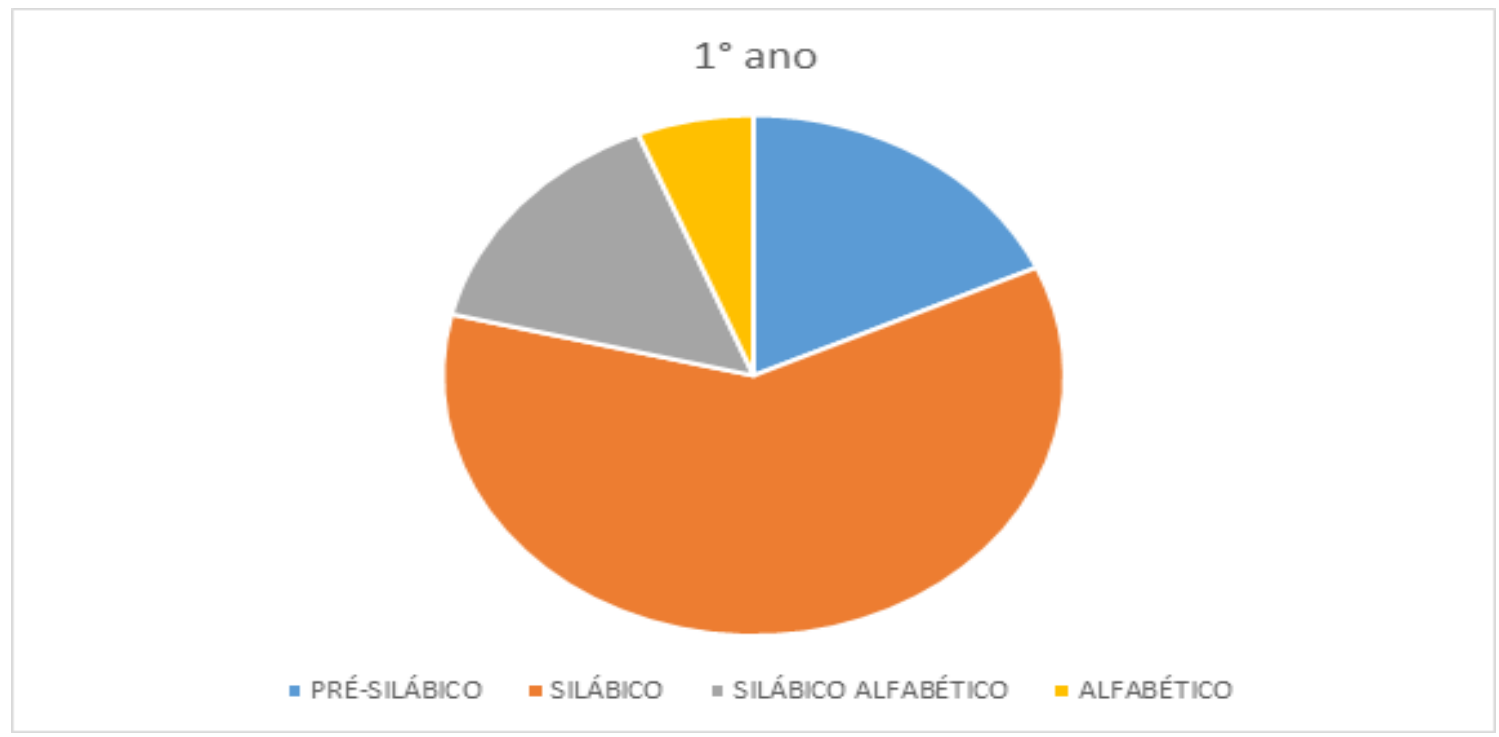

\section{Gráfico 2:}

Turma de $2^{\circ}$ ano 
- Nível Pré-silábico: 2 alunos (II\%)

- Nível silábico: 5 alunos (26\%)

- Nível silábico-alfabético: 1o alunos (53\%)

- Nível alfabético: 2 alunos (II\%)

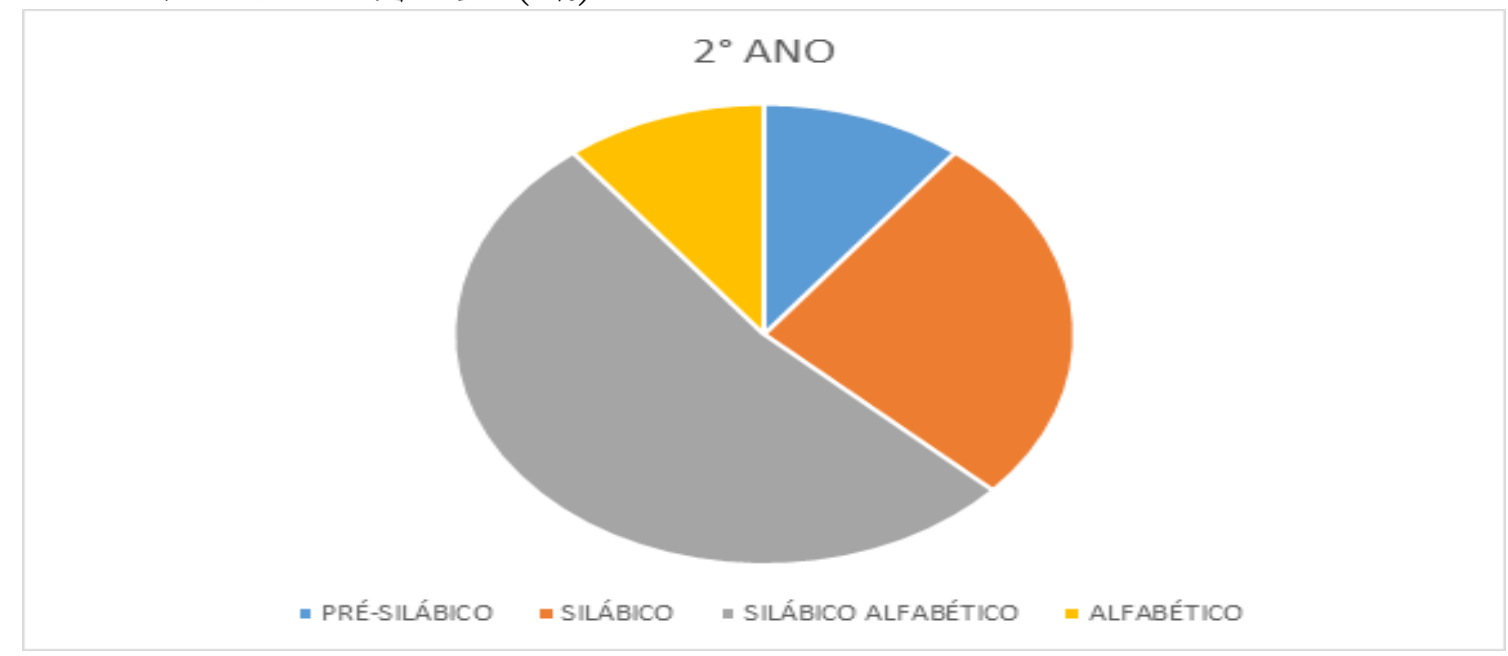

Nível de Leitura

Gráfico 3:

Turmas de $\mathrm{I}^{\circ}$ ano:

- Não lê: 6 alunos (I8\%)

- Lê silabando: 2I (63\%)

- Lê textos sem fluência: 5 (15\%)

- Lê textos com fluência: I (3\%)

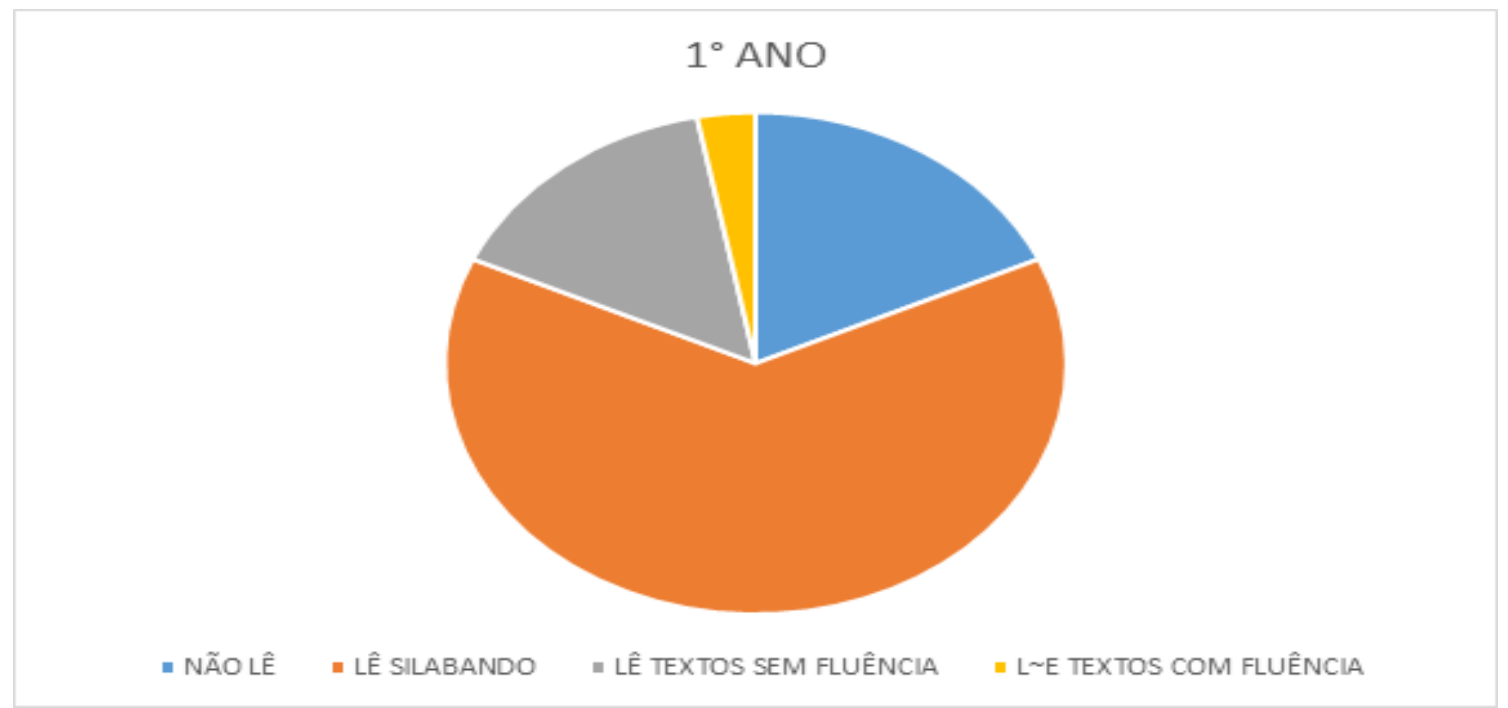

Gráfico 4:

Turma de $2^{\circ}$ ano: 
- Não lê: 3 alunos (16\%)

- Lê silabando: 7 (37\%)

- Lê textos sem fluência: 6 (32\%)

- Lê textos com fluência: 3 (16\%)

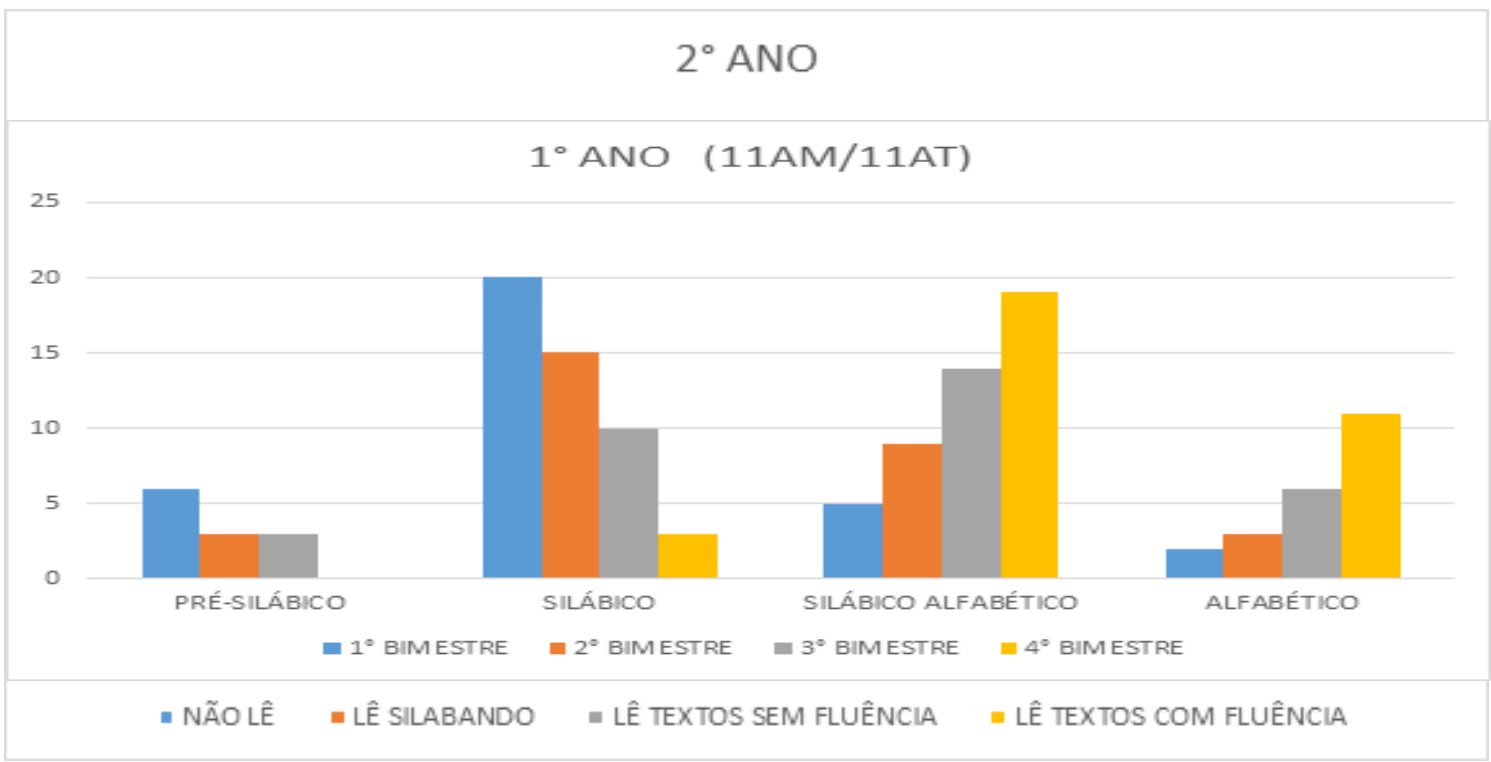

Gráfico 5: Quantidade de alunos do $\mathrm{I}^{\circ}$ ano em cada nível de Escrita avaliados ao longode cada bimestre de 2018:

Gráfico 6: Quantidade de alunos do $2^{\circ}$ ano em cada nível de Escrita avaliados ao longode cada bimestre de 2018:

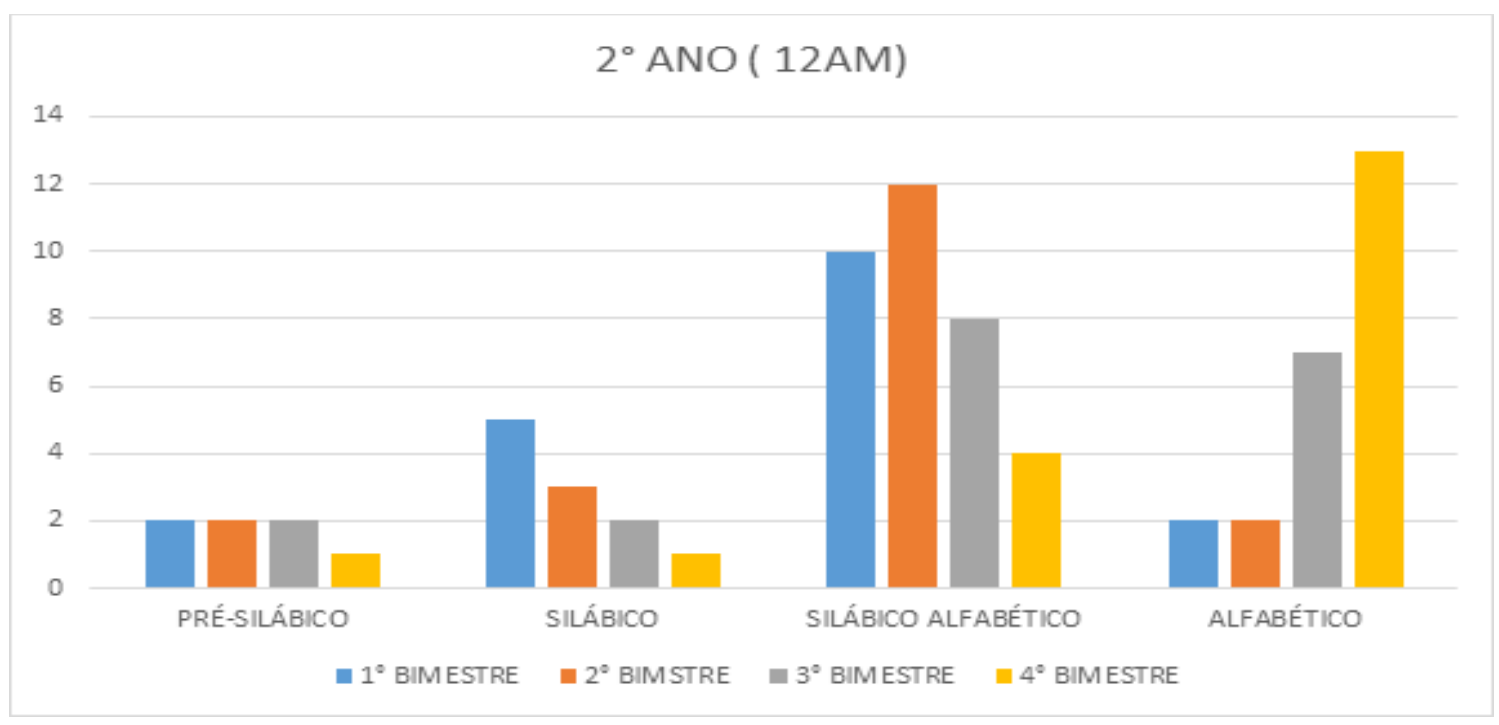


Gráfico 7: Quantidade de alunos do $\mathrm{I}^{\circ}$ ano em cada nível de Leitura avaliados ao longode cada bimestre de 2018:

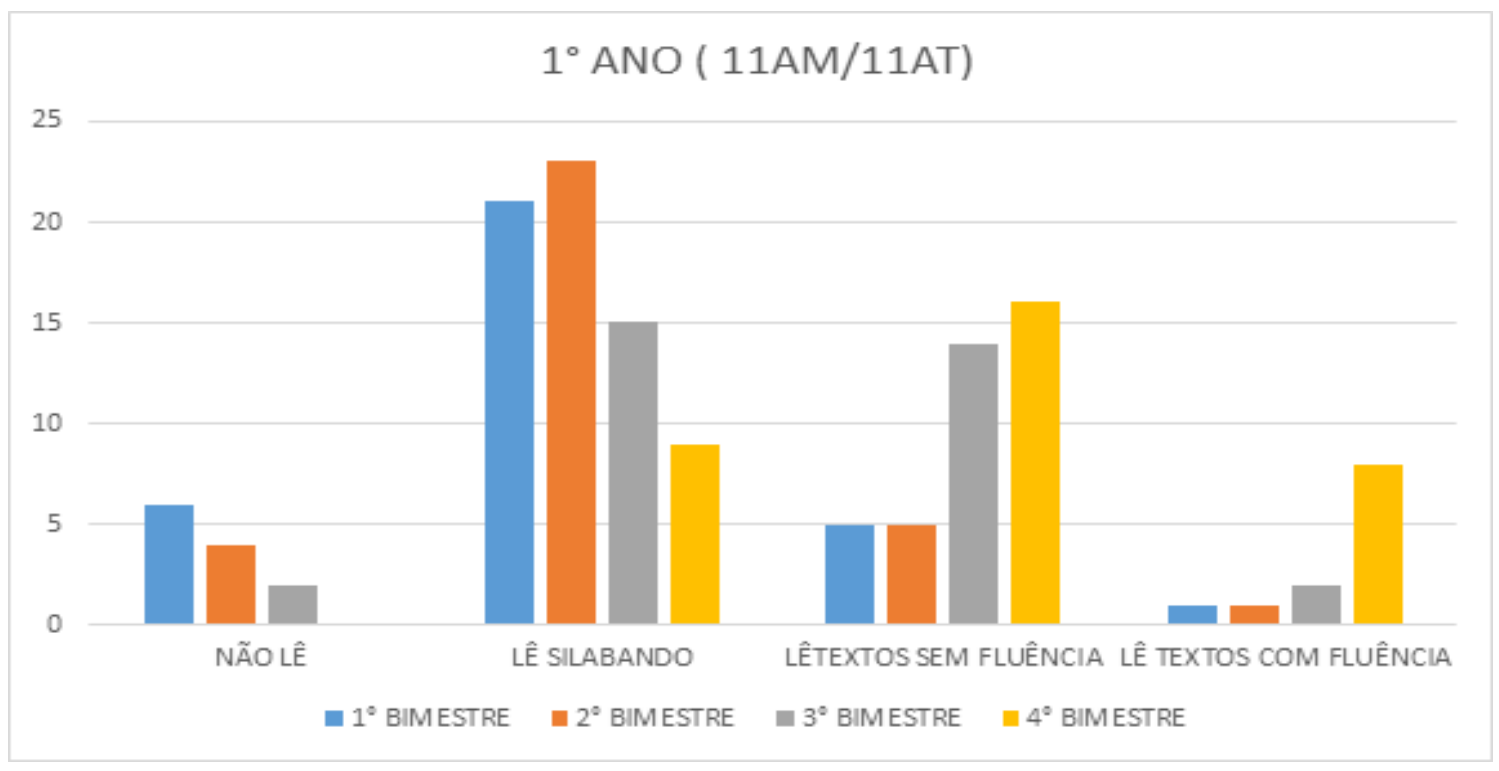

Gráfico 8: Quantidade de alunos do $2^{\circ}$ ano em cada nível de Leitura avaliados ao longode cada bimestre de 2018:

\section{$2^{\circ} \mathrm{ANO}(12 \mathrm{AM})$}

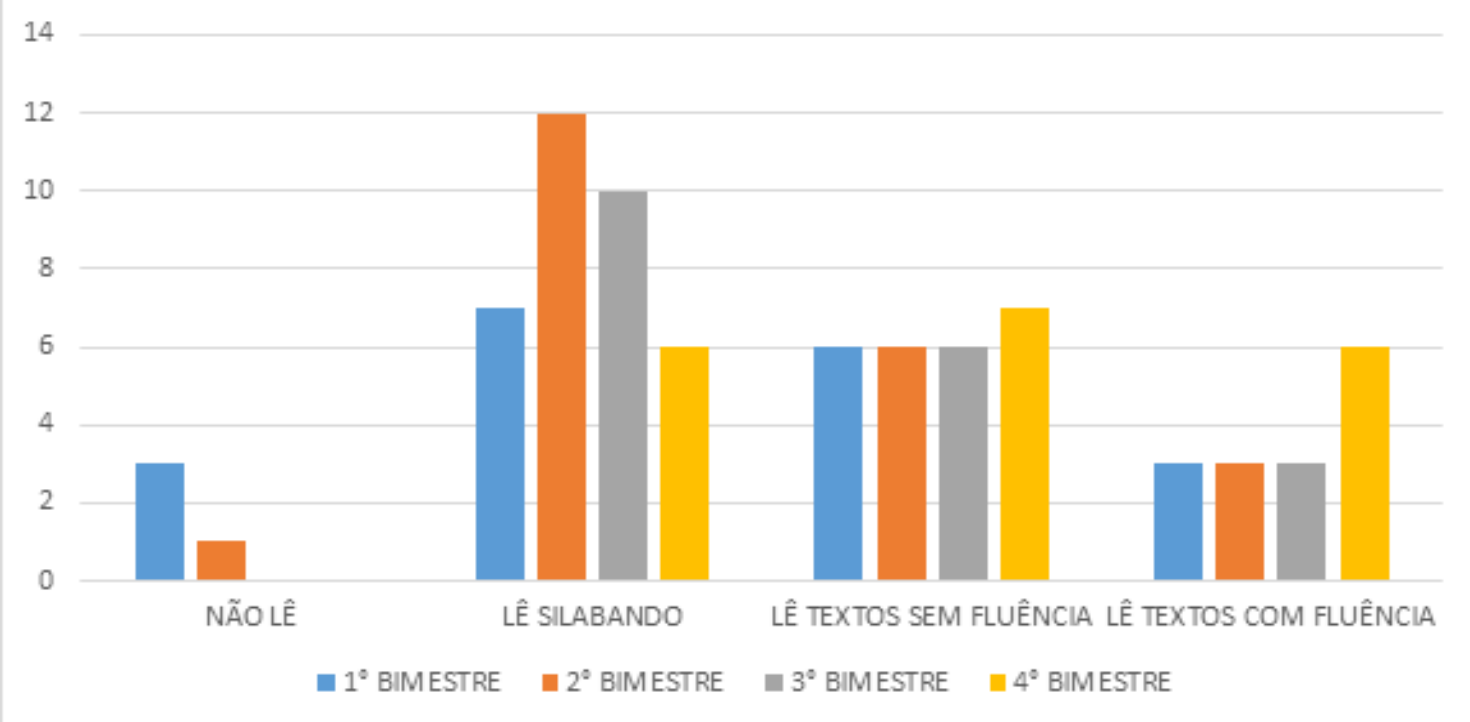




\section{REFERÊNCIAS BIBLIOGRÁFICAS}

Alves. Rubem, A alegria de ensinar. Campinas, SP: Papirus; Rubem Alves M. E. 20oo.https://www.uniavan.edu.br/uploads/arquivo/cHizLMs.pdf

BARBOSA, Áureo José. Compreensão dos direitos de aprendizagem por uma Professora Alfabetizadora: caminhos da prática docente para o trabalho com a leitura nociclo de alfabetização/ Áureo José Barbosa - 2017.

http://www.ceale.fae.ufmg.br/pesquisas/view/1902

Benavot, A. Argumentos en favor de la alfabetización. Educación de adultos y Desarrollo: Ediciones. EAD 71. Reflexiones Internacionales sobre aspectos derivados de los puntos de referenciia y del llamamiento a la acción. 2008. https://www.dvvinternational.de/es/educacion-de-adultos-y-desarrollo/ediciones/ead-71 2008/reflexiones-internacionales-sobre-aspectos-derivados-de-los-puntos-dereferencia-y-del-llamamiento-a-la-accion/argumentos-en-favor-de-la-alfabetizacion

Brasil. Lei de Diretrizes e Bases da Educação Nacional. Lei número 9394, 20 de dezembro de 1996.http://www.planalto.gov.br/ccivil_03/leis/l9394.htm

Ferreiro, E.; Teberosky, A Psicogênese da Língua escrita. Porto Alegre: Artes Médicas, I986.https://acervodigital.unesp.br/bitstream/123456789/40138/r/ordi6to3.pdf

Goleman, D. (1999). La práctica de la inteligencia emocional. Barcelona. Kairós.

Gutiérrez, M. C., \& López, J. E. (2015). Autoconcepto, dificultades interpersonales, habilidades sociales y conductas asertivas en adolescentes. Revista Española de

Orientación y Psicopedagogía, 26(2), 42-58.

http://revistas.uned.es/index.php/reop/article/view/

I5215

Freire. Paulo. Pedagogia da autonomia: saberes necessários à prática educativa. São Paulo: Paz e terra, 1996.

Fernández-Berrocal, P., y Extremera, N. (2002). La inteligencia emocional como unahabilidad esencial en la escuela. Revista Iberoamericana de Educación, 29, I-6. https://rieoei.org/RIE/article/view/2869

https://cidades.ibge.gov.br/brasil/pi/teresina

https://cidades.ibge.gov.br/brasil/pi/teresina/panorama 
http://www.planalto.gov.br/ccivil_03/_Ato2004-2006/2006/Lei/Lir274.htm

Site do Instituto Alfa e Beto http://www.alfaebeto.org.br/

http://basenacionalcomum.mec.gov.br/abase/

http://www.portalpmt.teresina.pi.gov.br/pagina/Teresina/I

https://educador.brasilescola.uol.com.br/trabalho-

docente/alfabetizacao.htm https://www.espacoeducar.net/20II/o6/ditado-

doce-atividades-doces-com.html

https://www.espacoeducar.net/2011/o6/alfabeto-pega-peixe.html

Ferreira, D. ( $\mathrm{s} / \mathrm{d})$ Aprenda brincando com o ditado estourado. https://www.papodaprofessoradenise.com.br/aprenda-brincando-com-o-ditadoestourad o/Medina, M. B. E. (2015). Influencia de la interacción alumno-docente en el proceso enseñanza-aprendizaje. Paakat: Revista de Tecnología y Sociedad, (8).http://www.udgvirtual.udg.mx/paakat/index.php/paakat/article/view/230/34

Métodos de pesquisa / [organizado por] Tatiana Engel Gerhardt e Denise Tolfo Silveira ; coordenado pela Universidade Aberta do Brasil - UAB/UFRGS e pelo Curso de Graduação Tecnológica - Planejamento e Gestão para o Desenvolvimento Rural da SEAD/UFRGS. - Porto Alegre: Editora da UFRGS, 2009.

Morente, A. R., Guiu, G. F., Castells, R. R., \& Escoda, N. P. (2017). Análisis de la relación entre competencias emocionales, autoestima, clima de aula, rendimiento académico y nivel de bienestar en educación primaria. Revista Española de Orientación y Psicopedagogía, 28(I), 8-18. https://www.redalyc.org/pdf/3382/338252055002.pdf

REVISTA USP • São Paulo • n. Ioo • p. 21-32 • DEZEMBRO/JANEIRO/FEVEREIRO 2013-2014.22.Dossiê Educação. Resumo.

Skinner, Burrhus Frederic. Tecnologia do ensino. Tradução de Rodolpho Azzi. SãoPaulo: EPU/EDUSP, 1972. Título original: The technology of teaching.

Vygotsky, Lev Semenovich. A formação social da mente: o desenvolvimento dos processos psicológicos superiores. Tradução de José Cipolla Neto, Luis Silveira Menna 
Barreto, Solange Castro Afeche. $4^{\underline{a}}$ edição. São Paulo: Martins Fontes, 199ı. Título original: Mind in society: the development of higher psychological process.

Yavorski, R., \& Santos e Campos, M. (2019). Formación docente: la formación delprofesor y la influencia sobre el aprendizaje de los alumnos. MLS Educational Research, 3(I). https://doi.org/https://doi.org/I0.29314/mlser.v3ir.7o 